\title{
How to use visual methods to promote health among adolescents: A qualitative study of school nursing
}

\author{
Authors \\ Hilde Laholt ${ }^{1}$, Marilys Guillemin ${ }^{2}$, Kim McLeod ${ }^{3}$, Ellinor Beddari ${ }^{1}$, Geir Lorem ${ }^{1}$

\section{Institutions} \\ ${ }^{1}$ UiT The Arctic University of Norway, Tromsø, Norway, ${ }^{2}$ University of Melbourne, Australia, \\ ${ }^{3}$ University of Tasmania, Australia
}

Corresponding Author: Hilde Laholt; hilde.laholt@uit.no +47 77660725

Short Title: Use of visual methods in school nursing

Key words: adolescents, dropout, health promotion, photovoice, public health, public health nurses, school nursing, visual methods

Acknowledgements: The authors would like to thank the study participants for their contributions and Randi Elisabeth Olsen for assistance in planning and conducting the study.

Declaration of conflicting interests: The author(s) declare no potential conflicts of interest with respect to the research, authorship, and/or publication of this article.

This is the author manuscript accepted for publication and has undergone full peer review but has not been through the copyediting, typesetting, pagination and proofreading process, which may lead to differences between this version and the Version of Record. Please cite this article as doi: $\underline{10.1111 / J O C N .14878}$

This article is protected by copyright. All rights reserved 
MRS. HILDE LAHOLT (Orcid ID : 0000-0001-9169-6813)

Article type : Original Article

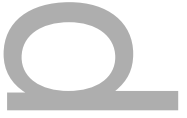

Abstract

Aims. Public health nurses attended a three-day course to learn the use of visual methods in health dialogue with adolescents. The aim of this study was to explore how to use visual methods to promote health among adolescents in a school nursing context.

Background. Photovoice is a visualizing technique that enables adolescents to participate in health promotion projects in a school setting. Photovoice also enhances work of public health nurses and other health professionals.

Design. This was a qualitative action research study. We developed and conducted a course in visual methods and utilized data from focus group discussions in combination with participant observations involving public health nurses working in school health services.

Methods. We conducted focus group interviews $(n=40)$ using separate semi-structured discussion guides before and after a course in visual methods. The interviews were audio recorded and transcribed verbatim, and we documented the workshops $(n=8)$ through field notes. We collected the data from January to October 2016. Data were analysed and coded into themes and subthemes using systematic text condensation. We reported the study in accordance with the COREQ checklist.

Findings. Public health nurses found photovoice useful in school nursing. The use of images offered pupils an active role in dialogues, and more control in defining the topics and presenting their stories. When nurses allowed adolescents to bring images into conversations, they discovered new insights into public health promotion. The public health nurses pointed out the benefits and challenges of using new methods in practice.

Conclusion. Public health nurses considered photovoice to be useful in health promotion and other public health issues. Involving pupils in bringing images to conversations offered them an active role and voice in health promotion.

Relevance to clinical practice. We recommend the use of photovoice and visual technologies (e.g. smartphones) in health promotion activities for adolescents. 


\section{What does this paper contribute to the wider global community?}

- Important knowledge about how nurses and other health professionals can involve adolescents and offer them an active role in health promotion by using visual technologies and bringing images to conversations.

- Knowledge about how visual methods and photovoice are useful and relevant to public health issues in school nursing contexts.

- Discussions on how to use visual methods as one avenue for public health nurses to achieve their health promotion aims.

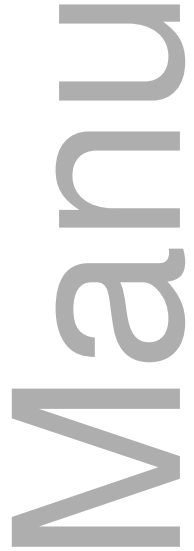

\section{Introduction}

Working with adolescents in a health care context can be challenging and one of our focus areas is to overcome potential communication barriers between adults and adolescents. Public health nurses (PHNs) in Norway have a key role in health promotion and disease prevention through their school health dialogues with children and young adults (6-20 years) throughout their schooling (Norwegian Directorate of Health, 2017). The health dialogue is a conversation between the PHN and pupils that can follow set guidelines, or alternatively be an open-ended discussion with individual pupils or groups about their health or developmental concerns (Borup, 2002; Norwegian Directorate of Health, 2017). Health promotion is a process where the focus is on the positive, dynamic and empowering aspects of health This article is protected by copyright. All rights reserved 
(Eriksson \& Lindstrom, 2008). The role of health promotion in school nursing is to activate resources and provide appropriate skills for pupils to deal with life's challenges. School PHNs aim to promote the health of all pupils in a school environment, and being their 'spokesperson' is a part of this role (Norwegian Directorate of Health, 2017). However, the Norwegian guidelines for health clinics and school health services provide no established methods or programme for use at the public health level to achieve these goals. In this paper we explore visual methods as one avenue for PHNs to achieve their health promotion aims.

\section{Background}

The use of visual methods offers adolescents the potential to actively participate in health promotion in a school setting. Visual methods are used in social and health research; examples are photovoice, drawings, images, films and videos, artwork and photo elicitation (Guillemin, 2004; McLeod, 2017; Rose, 2012; Wang \& Burris, 1994). We explore the use of a course to teach visual methods including photovoice to enhance school PHNs' toolbox for use in health promotion with pupils. Wang and Burris (1994) used photo novella or photovoice where people create and discuss photographic images with the aim of improving or changing issues they considered important in their lives or social context. In the original photovoice projects, participants were given access to traditional cameras and taught to take photographs (Wang \& Burris, 1994; Wang et al.,1998). The participants then discussed and analysed the images in groups, and presented the visual material in a group setting. Traditionally, photovoice was used to engage marginalized people, giving them voice and an opportunity to communicate community needs and concerns to service providers and policymakers (Wang \& Burris, 1994). Using photovoice or digital storytelling can allow people to convey meaning, emotions and struggles that cannot easily be expressed through verbal dialogue (Ginicola, 2012; Wang \& Burris, 1994). This process of participation was based on an adaption of Paulo Freire's Pedagogy of the oppressed to health promotion and education (Freire, 1970). We suggest that utilizing principles from the photovoice method could be beneficial as a health promotion strategy for PHNs working in schools. In this study, pupils were asked to bring smartphone images for use in school health dialogues and present these in an exhibition as a way of focusing on relevant public health issues. The photovoice technique has the potential for PHNs and other health professionals to enhance their public health work and enables young people to participate in health promotion projects. 


\section{The study}

Aims. PHNs were given a three-day course to learn how to utilize visual methods in health dialogue with adolescents. The aim of this study was to explore how to use visual methods to promote health among adolescents in a school nursing context.

\section{Design and methods}

We developed and conducted a course in visual methods for PHNs working in school health services in Troms $\varnothing$, a city of 75,000 inhabitants in northern Norway. Approval was gained from the head of the public health nursing services in Troms $\varnothing$. The Norwegian Centre for Research Data reviewed and approved the project on 8 September 2015 (NSD: Ref. No. 4439). The project was first presented at established professional meetings, with almost all the PHNs (about 60) working in the local authority present. We explained that participation was voluntary and sought consent for participation. The participants were all female registered nurses with further education as PHNs, with an experience range from 0.4-34 years in school nursing. The participants worked as PHNs with disease prevention and health promotion in child health clinics (0-5 years), adolescent health clinics (13-20 years) and school health services (pupils 6-20 years).

We used an action research approach involving focus group discussions (FGDs) in combination with participant observation and workshops on the use of visual methods (Emerson et al., 2011; Krueger \& Casey, 2014; McNiff, 2014). The action research study comprised three phases. In total 40 PHNs participated in the study; subgroups with different numbers of PHNs participated in the different phases of the study. In the first phase, 31 PHNs participated in FGDs to explore their previous experience and knowledge of visual methods. In the second phase, 39 PHNs participated in workshops to further develop the use of visual methods in school nursing. Our observations (transcripts and notes) documented the experiences, feedback and progress of the workshops. Finally, 9 PHNs took part in FGDs to explore the PHNs' experiences with visual methods, the workshops and their general assessment of visualization in school nursing. Most of the participants participated in more than one phase.

This article is protected by copyright. All rights reserved 
The 31 PHNs in the first phase of the study comprised about half of the total number of PHNs working in Troms $\varnothing$ during the project period (FGD1 n=5, FGD2 n=5, FGD3 n=11, FGD4 n=6 and FGD5 n=4). We organized FGD 1-5 at four different child health clinics in Troms $\varnothing$.

In the second phase of the study, the workshop series included all the FGD participants along with additional eight PHNs $(n=39)$. The workshop series was designed to train PHNs in utilizing different visual methods. We divided the participants into five subgroups to undertake different visual methods: drawing, photo elicitation, sensory elicitation, photovoice and a group working with a wellbeing chart. The focus in this paper is on the photovoice findings. Eight PHNs participated in the photovoice group, five of whom participated in phase 1 and two in the final FGD phase. The training in the workshops enabled the PHNs to enhance their skills in how to encourage people to present their story through visualization. When discussing images and stories in the group, PHNs developed their knowledge of photovoice with their peers. In this workshop, the PHNs were asked to engage young adults to share images visualizing 'drop out from high school' and 'why young adults want to stay in school'. The PHNs chose this task because dropout from high school is a problematic public health issue in Norway (Bania et al., 2016; De Ridder et al., 2012). Several PHNs participating in the study had experience of dropout in their school nursing practice.

In the third phase of the study, we included nine PHNs into two FGDs (FGD6, n=4 and FGD7, $n=5$ ). We organized these FGDs at the university campus. We conducted the focus groups and course on Fridays, the usual meeting day for the PHNs. Recruiting to the study by taking over existing meeting days made it easier to ensure attendance.

In this study, we used an adaptation of the photovoice method. The eight PHNs participating in the photovoice workshop took photographs with related stories and discussed the visual material in the workshop sessions. They engaged young adults to bring photographs and related stories of dropout, but did not form groups of pupils to discuss the images. After several rounds of encouraging PHNs to recruit adolescents, we received 10 photographs. Finally, we decided to cancel our plan of making an exhibition, because we considered the material too small for a representative presentation. We conducted and reported the study in accordance with the consolidated criteria for reporting qualitative research (COREQ) (Tong et al., 2007) (See Supplementary File 1).

This article is protected by copyright. All rights reserved 


\section{Data collection}

The data consisted of the seven focus group discussions $(n=40)$ as well as participant observations from the photovoice workshop $(n=8)$ and descriptions of the photographic images collected through the workshop in photovoice (images made by young people) (Krueger \& Casey, 2014; Madison, 2011). The data were collected from January to October 2016. The first author with an additional observer and co-moderator present moderated in all focus groups. At the beginning of FGDs 1-5, we explained the intention of the focus groups and the visual methods course. We used a semi-structured guide focusing on the school health dialogue, PHNs' use of visualization in school nursing, ethical issues and adolescents' use of visual technologies. In FGDs 6 and 7 we used a different discussion guide; here, we discussed PHNs' experiences of attending the course, PHNs' perception of ethical issues related to visual methods, and public health nursing at the group and public health levels. The first author audiotaped and transcribed the FGDs verbatim. We documented our observations of the course and workshops through field notes. The participants in the photovoice workshop discussed their experiences of using the photovoice method in nursing projects. We did not seek permission from the pupils to reproduce their images in publications and are thus unable to show them. Therefore, only descriptions of the images were provided. The data was organized using NVivo 11 (QSR International Pty Ltd, 2015).

\section{Data analysis}

We analysed the transcripts of FGDs, field notes, and descriptions of images using the principles of systematic text condensation (Malterud, 2012). Systematic text condensation is a qualitative analytical method that draws on Giorgi's psychological phenomenological analysis and consists of four steps. In the first step, we formed a general impression of the material, "from chaos to themes". The first author read the 120 pages to gain a general impression of the material, and developed tentative themes that ran through the entire data. In this stage of analysis, we looked for preliminary themes associated with how visual methods might influence the school health dialogue. In step 2, the themes were identified and coded from the texts; the coded data were then condensed and abstracted in each of the categories. The transcripts were organized using NVivo 11 (QSR International Pty Ltd, 2015) to identify meaning units, which are text fragments containing information relevant to the aim of the study. The coding procedure at this stage is flexible. In step 3 , the research team collaborated 
and reduced the empirical data to a selection of meaning units sorted as thematic code groups. We read the texts, recoded the data, and abstracted them. We reconceptualised the data in step 4 , and put the pieces together again. The analysis resulted in three key findings discussed in the following section.

\section{Findings}

The first analytical reading of the data revealed five preliminary themes: how to use visual methods in the health dialogue, challenges related to new methods, being more visible in schools, being spokespersons for young people, and using the PHN role in public health. These were condensed into the final three key findings, which were a result of moving back and forth between transcripts, field notes, descriptions of images, findings, and theory in order to provide descriptions grounded in the empirical data. We present the three key final findings, as: use of photovoice gave young people a more active role in health promotion, usefulness of photovoice to focus on public health issues and benefits and challenges of implementing new methods in school nursing.

PHNs found photovoice to be useful for focusing on public health issues. When PHNs allowed adolescents to bring images into conversations, they discovered new insights on public health issues relevant to health promotion. The use of images offered pupils a more active role in dialogues, and more control in defining the topics and presenting their stories. Photovoice allowed PHNs to be spokespersons for young people. The PHNs also pointed out the benefits and challenges of using visual methods in school nursing practice.

\section{Use of photovoice gave adolescents a more active role in health promotion}

In the workshop sessions, we encouraged the PHNs to utilize photovoice in their school nursing practices. They were asked to encourage pupils to take images with their smartphones, mobile phones or cameras illustrating 'dropout from high school'. After some discussion, the photovoice group agreed to expand the theme of 'dropout' to 'what makes pupils want to stay in school'. The PHNs decided to supplement the general topic of 'dropout' with more specific questions for the pupils to respond to with images and stories. Through the sessions, we found that the PHNs chose to solve the photovoice dropout task in different ways. Some directly asked pupils they knew to bring images and others collaborated with a teacher to recruit pupils to take images. The pupils also responded to the dropout task in 
different ways. For some, photography was a hobby, and they brought smartphone photographs from their school context. One of these was an arranged black and white image showing an adolescent in a hooded sweater throwing schoolbooks over his shoulder. The caption read: "Sometimes when time gets rough and your breath goes too fast. Your hands will shake. You will throw away all the emptiness, and drop out". This image showed the existential aspects of dropout, visualizing no return into the school system. Another PHN collaborated with a teacher in an introductory class for refugees and young people speaking foreign languages. This PHN showed a photograph where a young adult was examining his friends' teeth. The text said that he wanted to become a dentist, so he had to finish high school and study for nine more years before he could reach his goal. He was prepared to fight and work hard and that friendship was essential. This visual image represented a pupil's long-term goals and personal ambitions, and his motivation for staying in the school system. One PHN collaborated with a teacher in a class combining sports and study. This teacher encouraged her pupils to take photographs in a kind of competition. She said, "You got ten minutes to give photos to your nurse, just do it!" From these pupils we received several images; these were more spontaneous in nature but some were also very expressive. One of them presented young people stretching their arms together on a mountaintop, and pupils on skis. An image entitled 'unity' showed pupils in their classroom. One image presented a girl reading a book while dribbling a football. A black and white image called 'friendship' presented three smiling young boys; one was hanging on his friend's shoulder playfully wrestling, while the third was standing alongside. These images showed the importance of a positive school environment and a sense of belonging. Another image entitled 'bored 'n' tired' presented a book that replaced a young person's head. In the pose, he appeared to be asleep under the book. This image showed pupils' creativity and sense of humour. All pupils who provided photographs gave written consent allowing us to use their images in a future community exhibition. After discussing the incentive methods with the pupils, we chose to announce the photovoice project as a competition. The pupils with the best photograph received a gift card worth USD 120 , the second best a gift card worth USD 60. Seven pupils got gift cards worth USD 24. All nine participants thus received a participation prize. The photographs provided by the adolescents were a part of an internal photo competition, and the data were based on our observations of the PHNs and their work in the photovoice workshop. Therefore, we did not seek permission from the pupils to reproduce their images in publications, and we only quote descriptions of the images that our participants gave in this article. The adolescents that participated were aware that these activities were part of a research project. It should also be This article is protected by copyright. All rights reserved 
noted that due to various constraints, PHNs were not able to bring pupils together in groups after they had taken their images for discussion and identification of relevant concerns.

We found that the dropout project revealed that young people created and shared photographs when encouraged and found the task interesting. Some pupils focused on the emotional aspects of dropping out of high school, while others presented visual material illustrating friendship and positive activities associated with staying in school. The use of images offered pupils a more active role in health promotion and more control in defining the topics and presenting stories from their point of view.

\section{Usefulness of photovoice to focus on public health issues}

The PHNs found photovoice relevant when focusing on public health issues of importance for young adults. One PHN said, "We need to change things, not only at an individual level, but also at the group and public health level." The PHNs stated that being a spokesperson for young people was part of their school nursing role. One said, "We see many new trends related to teenage culture before the news appears in the media. I think we have an obligation to speak out about what we see, and we must have the guts to use this knowledge and communicate it to the media, administrators and politicians in our community". Another PHN said, "It's useful to present young people's stories and challenges through different channels; photovoice is such a channel". Several PHNs communicated that visualization could present young people's views on health issues that were of relevance for them and to youth culture. PHNs could collaborate with young people and encourage them to take images and make an exhibition at school. One PHN said, "Photovoice is relevant because we can show the world how things are for young people. Through a presentation we may understand a small part of what it's like to be young, using this knowledge on the adolescents' own terms". The PHNs also stated that photovoice could present young people from other cultures with the aim of understanding them better. Presenting these through an exhibition could be a way of integrating them into the high school system. One PHN said, "In my opinion, a presentation could mean quite a lot for these groups of young people". We found that the photovoice technique could enhance the PHN's role as spokesperson and advocate for young people, in addition to its benefits in promoting health.

\section{Benefits and challenges of implementing new methods in school nursing}


The PHNs were aware of both positive and negative aspects of utilizing visual methods in school nursing practice. One PHN said, "I see that using visual methods in the school health dialogue could make a difference to the relationship between us and the pupils. Adolescents show who they are through images and films. Youth culture is about sharing". We found that photovoice enabled young people to participate in health promotion projects and PHNs to explore and contribute towards public health issues. The PHNs wanted to raise the focus on public health issues and were keen on expanding the advocacy part of their role.

Some PHNs stated their concerns about introducing new methods in practice. One PHN said, "Almost all PHNs are positive towards new methods like photovoice and want to learn how to use them in practice. However, it is important to be critical and reflect so the tools don 't take over. A new method can`t be a substitute for dialogue and relationship building between PHNs and young people". Some PHNs underlined the importance of remaining critical when introducing new tools in school nursing. One PHN said, "We must be aware so we do not become a toolkit of methods, digital things and games. We have to be critical thinkers". The PHNs expressed the importance of utilizing new methods with care, and remaining critical when implementing a tool in practice.

\section{Discussion}

We found that PHNs considered photovoice to be a useful supplement for use in school nursing practice. The use of images offered adolescents a more active role in health promotion, and new ways to communicate about public health issues. Asking young people to bring images was a useful addition to the repertoire of PHNs working in schools. We also found that the PHNs wanted to expand their role as spokespersons for pupils in the school system. Photovoice enabled different considerations of public health issues relevant for young adults. The PHNs also pointed out the benefits and challenges of using visual methods in practice.

\section{How can photovoice enhance school nursing?}

PHNs participating in the photovoice workshop chose the 'dropout' challenge as a training task because they wanted to work on a public health issue that was relevant for their practice in school. Of the 66000 Norwegian adolescents that started high school in autumn 2012, $74.5 \%$ had completed while $25.5 \%$ had dropped out by 2017 (Statistics Norway, 2018). In our 
study, the images presented examples of why pupils would or would not drop out from school. Some of the pupils that provided images presented schoolwork as almost completely boring. This was visualized by the images of a pupil asleep under a book and another pupil throwing schoolbooks over his shoulder. However, these images also showed young peoples' creativity and sense of humour. The visual material of classmates in a classroom titled 'unity', 'pupils on skis', 'a girl dribbling a football' and 'smiling teenagers' showed young adults' views on resilience factors when remaining in a complex school system. The image where the boy examined his friend's teeth visualized a pupil's long-term goals of an academic education and his motivation for staying at school.

One main element of the photovoice method is to bring people together in groups allowing them to discuss and reflect on the content of their visual material. We did not ask the PHNs in our study to bring pupils together in groups after they had taken their images for discussion and identification of relevant concerns. However, when discussing images and stories in the workshop group, PHNs developed their knowledge of photovoice with their peers. This training enhanced their skills in how to encourage adolescents to present their story through visualization. Although the group discussion element of photovoice could not be incorporated in this study, group health dialogues with a PHN would allow pupils to discuss their images with their peers. The group leader could promote health by focusing on their resources and the positive aspects of staying at school (Norwegian Directorate of Health, 2017). We know that pupils may inspire each other to talk more openly in group sessions (Borup, 2002). Here, the focus will be on the sense of belonging in a group, the importance of cooperating on activities, and forming relationships with others in the same situation. Young adults who have a goal in life can be role models for their peers. Empowerment implies that health professionals allow young people to define their own issues and suggest solutions. One aim of these group dialogues is to learn and reflect on different options in pupils' life paths, thus enabling them to make sound choices. Group dialogues are health promoting because pupils inspire and learn from each other, and these processes encourage them to communicate and focus on the positive sides of the school environment. By using images and involving humour in health promotion activities, PHNs can overcome some of the communication barriers between adults and adolescents. We consider using images to be a powerful way of communicating about important issues, and this process may promote changes in young people's lives (Wang \& Burris, 1994). Active use of visualization allows PHNs to reach atrisk groups and change the dynamics in health dialogues (Authors, 2017).

This article is protected by copyright. All rights reserved 
Wang and Burris (1994) presented photovoice as a method to allow marginalized groups to be 'voiced and heard'. We know that education has a strong impact on personal well-being, living conditions and health (Bania et al., 2016; Freudenberg \& Ruglis, 2007). There is an ongoing debate in Norway on how to prevent dropout to enable young people to use their resources, finish high school, study, and find a job to make a contribution to society. By asking pupils to create images to be used, the PHNs accepted them as competent actors, with essential knowledge and expertise in this public health challenge. However, due to the limited numbers of images produced, we were not able to exhibit the young people's reflections on dropout at the city council community centre or the university, as we had originally intended. Since photovoice was considered useful for discussing relevant public health issues, we recommended to the PHNs to take the opportunity to provoke discussion of public health issues by including images in the city's adolescent health centre, on the city council website, or through social media. This would be an effective and relevant way for PHNs and young people to communicate public health concerns and inform relevant stakeholders. In this way, school PHNs could use their advocacy and public health role in collaboration with pupils, thus using their mandate as 'societal actors' according to the Norwegian guidelines for health clinics and school health services (Norwegian Directorate of Health, 2017).

\section{Benefits and challenges of introducing new methods in school nursing}

Although the use of visual methods offers benefits to PHNs in school nursing, it also presents challenges around ethical issues and data security. In school nursing, PHNs must provide detailed information to pupils about the voluntary aspects of participating in visual projects. There are also ethical implications involved in how participants are presented in exhibitions involving images (Gubrium et al., 2014). Visual expressions can be more symbolic and direct, and ethical issues may arise when people or events that should remain private are identified. Participants identifiable in an image must consent to be a part of a presentation. Norwegian criminal law includes rules for sharing pictures, including the posting of photographs of others without their consent (Norwegian Penal Code, 2005). Ongoing communication between all participants involved in a project is required to address any potential ethical concerns. 
We have presented elsewhere how PHNs used a variety of visual methods as part of their school health dialogues with pupils, and how they were prepared to be flexible to solve challenges that arose in their caring practices (Authors, 2017; Authors, 2018). The PHNs in our study wanted to try new methods and approaches to improve their dialogues and the public health aspect of their school nursing practice. Although they wanted to use their knowledge and make an impression on relevant stakeholders, it was not easy in practice. We wanted to make an exhibition of dropout at the city council community centre or the university, but we had to cancel it because we considered the material too limited for a representative presentation. In spite of this, photovoice is a technique that enables school PHNs to work at the public health level, enhancing the advocacy part of their role. The use of visual methods is considered a relevant way to enable adolescents to become more active in conversations, and contribute to health promotion projects. The PHNs saw several benefits of introducing visual methods in practice. However, they also expressed the importance of utilizing new methods with care. Tools or methods can never replace relationship building or solve all communicative barriers between professionals and young people.

\section{Limitations}

This study had limitations related to the sample size, the use of the methods, and the use of field notes to document the course and workshops. Eight PHNs took part in the photovoice workshop. A limited number of pupils were involved in the dropout project and few images were produced (10). We found that the PHNs who chose to involve teachers in the recruitment process received most visual material. This experience suggests that we could have encouraged the PHNs to use teachers for recruitment of pupils.

An additional source of bias may have been some variation in the size of the focus groups. The smallest groups (FGD5, n=4) and (FGD6, n=4) may not have represented a wide enough range of experiences. FGD3 $(n=11)$ consisted of participants from two different child health clinics. This group may not have given all participants the opportunity to express their opinions.

In FGDs 1-5, our questions did not cover the PHNs' societal or public health role. However, our participants brought up this topic and communicated their intentions and wishes of 
developing and expanding this part of their role. Therefore, we chose to add a question to promote a discussion of the public health role in the second round of FGDs.

We should also point out that some elements of photovoice were not incorporated in our project. We did not encourage the PHNs to form groups of pupils to discuss the images, and we were unable to present the dropout project in a local exhibition. However, we consider our presentation of how we used photovoice to be useful for other professions working with adolescents and young adults.

We also see that there were limitations connected to our decision to document the workshop sessions through field notes. The group leaders wrote down their reflections after all workshop meetings. We may have lost some important issues from these discussions. There were also limitations in the fact that the moderator, co-moderators, and group leaders in the focus groups and workshops were PHNs themselves. They are experienced PHNs and teachers in the PHN master's degree course at UiT The Arctic University of Troms $\varnothing$ and knew several of the participants through their work in the small city as lecturers in health and both as "insiders" and "outsiders". However, the project group consisting of the three PHNs, two health sociologists and one philosopher collaborated in the different phases of the project, and documented all steps in the process. In the analytical process, the first author started the interpretation of the data, followed by collaboration with the research team until we reached agreement. The different perspectives may have influenced the interpretations of the material, and helped us to nuance the analysis process and ensure reliability (Malterud, 2001). The systematic steps of the analytical method and the presentation supported the validity of our findings (Tong et al., 2007).

\section{Conclusion}

Public health nurses considered photovoice to be useful in health promotion and relevant when focusing on public health issues. Involving pupils in bringing images to conversations offered them a more active role and voice in health promotion. Being an advocate for young adults in the field of public health is an important part of PHNs' societal role. Teaching PHNs, other nurses and social workers how to use visual methods could enhance their interests, enthusiasm and professional toolbox in public health work. 


\section{Relevance to clinical practice}

We consider this study relevant to nursing, other health professions and social work, as it can create interest in using photovoice and other visual methods when promoting adolescents' levels of health or health status at the individual, group and public health levels. Visual technologies could become an important feature of interactions between nurses and young adults. Therefore, we recommend the use of photo voice and visual technologies in health promotion activities related to young adults.

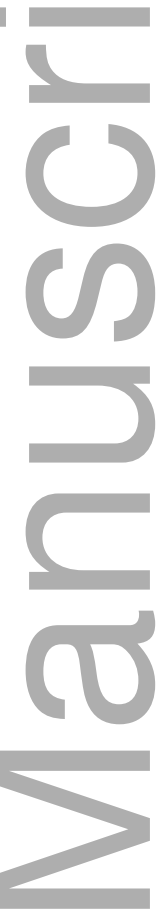

\section{References}

Bania, E. V., Lydersen, S., \& Kvernmo, S. (2016). Non-completion of upper secondary school among female and male young adults in an Arctic sociocultural context; the NAAHS study. BMC Public Health, 16(1), 960. https://doi.org/10.1186/s12889-016-3644-2 
Borup, I. (2002). The school health nurse's assessment of a successful health dialogue. Health and Social Care in the community, 10(1), 10-19. https://doi.org/10.1046/j.09660410.2001.00337.x

De Ridder, K. A. A., Pape, K., Johnsen, R., Westin, S., Holmen, T. L., \& Bjørngaard, J. H. (2012). School dropout: a major public health challenge: a 10-year prospective study on medical and non-medical social insurance benefits in young adulthood, the YoungHUNT 1 Study (Norway). Journal of Epidemiology and Community Health, 66(11), 995-1000. doi:10.1136/jech-2011-200047

Emerson, R. M., Fretz, R. I., \& Shaw, L. L. (2011). Writing ethnographic fieldnotes (2nd ed. ed.). Chicago: University of Chicago Press. doi:10.7208/chicago/9780226206851.001.0001

Eriksson, M., \& Lindstrom, B. (2008). A salutogenic interpretation of the Ottawa Charter. Health Promotion International, 23(2), 190-199. https://doi.org/10.1093/heapro/dan014

Freire, P. (1970). Cultural Action and Conscientization. Harvard Educational Review, 40(3), 452-477. https://doi.org/10.17763/haer.40.3.h76250x720j43175

Freudenberg, N., \& Ruglis, J. (2007). Reframing school dropout as a public health issue. Preventing Chronic Disease, 4(4). http://www.cdc.gov/pcd/issues/2007oct/07_0063.htm.

Ginicola, M. M. (2012). Counseling through images: Using photography to guide the counseling process and achieve treatment goals. Journal of Creativity in Mental Health, 7(4), 310-329. https://doi.org/10.1080/15401383.2012.739955

Gubrium, A. C., Hill, A. L., \& Flicker, S. (2014). A situated practice of ethics for participatory visual and digital methods in public health research and practice: a focus on digital storytelling. American Journal of Public Health, 104(9), 1606-1614. doi:10.2105/AJPH.2013.301310

Guillemin, M. (2004). Embodying heart disease through drawings. Health, 8(2), 223-239. https://doi.org/10.1177/1363459304041071

Krueger, R. A., \& Casey, M. A. (2014). Focus groups: A practical guide for applied research. Thousand Oaks, CA: Sage Publications.

. (2017). Visual methods in health dialogues: A qualitative study of public health nurse practice in schools. Journal of Advanced Nursing, 73(12), 3070-3078. https://doi:10.1111/jan.13371 
. (2018). Ethical challenges experienced by public health nurses related to adolescents' use of visual technologies. Nursing Ethics, https://doi.org/10.1177/0969733018779179

Madison, D. S. (2011). Critical ethnography: Method, ethics, and performance: Thousand Oaks, CA: Sage Publications. DOI: 10.1177/1532708610365476 http://csc.sagepub.com

Malterud, K. (2001). Qualitative research: standards, challenges, and guidelines. Lancet, 358(9280), 483-488. https://doi.org/10.1016/S0140-6736(01)05627-6

Malterud, K. (2012). Systematic text condensation: a strategy for qualitative analysis. Scandinavian Journal of Public Health, 40(8), 795-805. https://doi.org/10.1177/1403494812465030

McLeod, K. (2017). Wellbeing Machine: How health emerges from the assemblages of everydaylife. ISBN 978-1-61163-705-2: Carolina Academic Press. Retrieved from http://www.cap-press.com/books/isbn/9781611637052/.

McNiff, J. (2014). Writing and Doing Action Research. Los Angeles: Sage.

Norwegian Directorate of Health. (2017). Nasjonale retningslinjer for helsestasjon (0-5 år) skolehelsetjenesten (6-20 år) [National guidelines for health clinics (0-5 years) and school health services (6-20 years]. Oslo Retrieved from https://helsedirektoratet.no/retningslinjer/helsestasjons-og-skolehelsetjenesten.

Norwegian Penal Code. (2005). Lov om straff [Act relating to punishment] [Punishment Act] Amended 01.07.2017. Norway: Ministry of Justice and Public Security Retrieved from https://lovdata.no/dokument/NL/lov/2005-05-20-28/KAPITTEL_2-11\#§311.

QSR International Pty Ltd. (2015). NVivo qualitative data analysis software; QSR International Pty Ltd. Version 11.

Rose, G. (2012). Visual methodologies: an introduction to researching with visual materials. (3rd ed.). Los Angeles: Sage.

Statistics Norway. (2018). Completion rates of pupils in upper secondary school. Retrieved from https://www.ssb.no/en/utdanning/statistikker/vgogjen/aar.

Tong, A., Sainsbury, P., \& Craig, J. (2007). Consolidated criteria for reporting qualitative research (COREQ): a 32-item checklist for interviews and focus groups. International Journal for Quality in Health Care, 19(6), 349-357.

https://doi.org/10.1093/intqhc/mzm042

Wang, C., \& Burris, M. A. (1994). Empowerment through photo novella: portraits of participation. Health Education Quarterly, 21(2), 171-186. https://doi.org/10.1177/109019819402100204

This article is protected by copyright. All rights reserved 
Wang, C., Yi, W. K., Tao, Z. W., \& Carovano, K. (1998). Photovoice as a participatory health promotion strategy. Health Promotion International, 13(1), 75-86. https://doi.org/ 10.1093/heapro/13.1.75

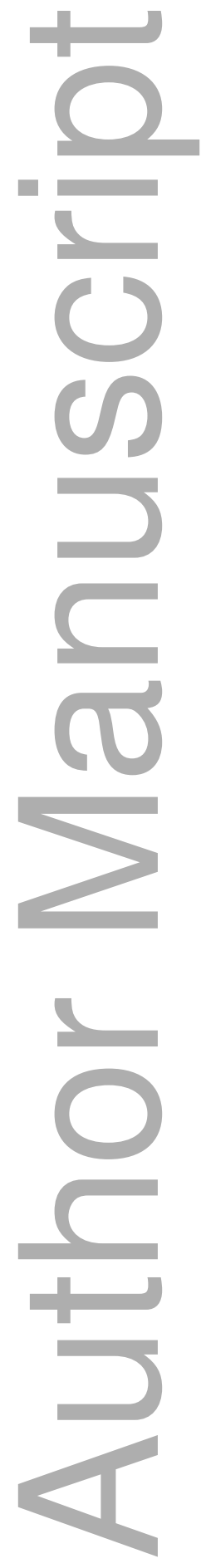




\section{University Library}

\section{- M M N E R VA A gateway to Melbourne's research publications}

Minerva Access is the Institutional Repository of The University of Melbourne

Author/s:

Laholt, H;Guillemin, M;McLeod, K;Beddari, E;Lorem, G

Title:

How to use visual methods to promote health among adolescents: A qualitative study of school nursing

Date:

2019-07-01

Citation:

Laholt, H., Guillemin, M., McLeod, K., Beddari, E. \& Lorem, G. (2019). How to use visual methods to promote health among adolescents: A qualitative study of school nursing. JOURNAL OF CLINICAL NURSING, 28 (13-14), pp.2688-2695. https://doi.org/10.1111/ jocn.14878.

Persistent Link:

http://hdl.handle.net/11343/285756 